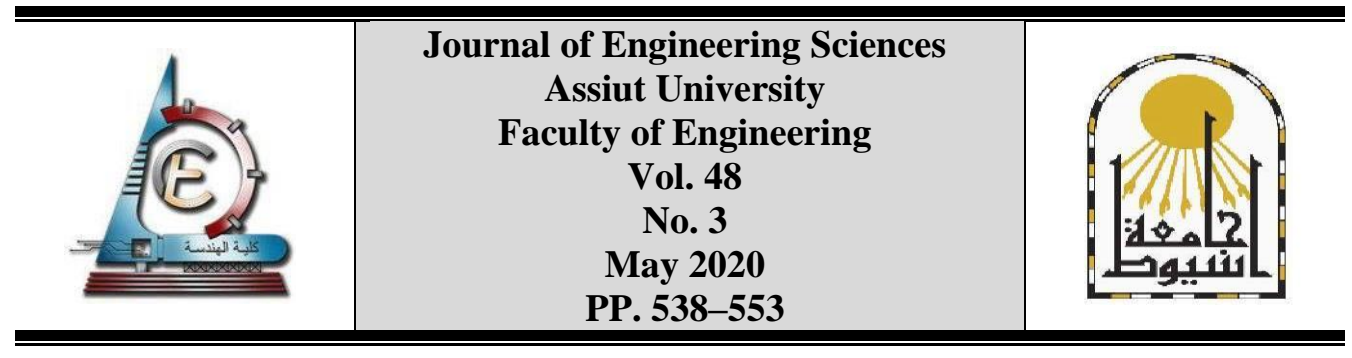

\title{
THE EGYPTIAN CITY CENTRES IN THE ISLAMIC ERA: IMAGE ANALYSIS, EVALUATION AND CONTEMPORARY REFLECTION
}

\author{
Lobna M. Moubarak \\ Architectural Eng. Depart, Faculty of Engineering, Aswan University, Aswan, Egypt \\ E-mail: lobna.mahmoud@aswu.edu.eg
}

Received 5 January 2020; Accepted 30 January 2020

\begin{abstract}
The central district of any Islamic city is the location of the most distinctive architectural and urban features. This district includes the important architectural monuments such as Friday mosques, bazaars, Khans and Madrasas. To analyse the image of the Egyptian city during the Islamic period, it is important to understand how Egyptian Muslims conceptualized and represented their cities and to clarify the forces and underlying causes that underpin the distinguished visual appearance of such cities. It is investigated here how the aspects of the Islamic version of the image of city centres in Egypt can be translated to certain concepts and codes which can be considered in the development of the image of contemporary city in order to regain its identity and achieve the visual sustainability. To achieve this aim, Lynch analysis is applied here to investigate the five components of the image of Islamic Egyptian city centre, and then it is evaluated against certain criteria. This paper aims also to identify the positive and negative aspects of the visual image of Egyptian city during the Islamic era by focusing on the overhead image as a method of city perception at the present. It is concluded here that the visual quality of the Islamic image of Egyptian city centre is affected by some negative aspects such as; shortage of accessibility, absence of legible streets network, closed fields of vision, and similarity and monotony of landmarks. But on the other hand, these aspects which can be interpreted to be negative are justified in terms of the religious, cultural, and social contexts of the Islamic era. The main principles of designing the Islamic city have been derived and clarified as certain concepts such as community-based city design, the balance between visual exposure and privacy, and design for climate. It is confirmed here that, to create a link between the design of the city image during the Islamic era and the contemporary version of the city image, these principles should be applied to the design of contemporary cities using the available new techniques in order to meet the different needs of users and to investigate these principles deeply to go beyond merely using the Islamic styles in buildings facades in order to achieve the resilience of such image to the different changes and challenges.
\end{abstract}

Keywords: Egyptian city image, Islamic city, Lynch analysis, urban design, Islamic architecture, Overhead image.

\section{Introduction}

The term "Egyptian Cities" evokes a multitude of images full of mosques, minarets, crowded coffee houses, public buildings and a high density of population and activities. In such cities, many contrasting scenes between modernity and tradition, private and public and complexity and simplicity can be observed. The design of the Egyptian city during the 
Islamic period had cultural, social and functional logics in terms of built objects, layouts and land uses which can be used as guidelines for modern planning and visual design of the city.

Because the morphology of the city is more than a form; it evokes the past, prefigures the future and expresses the present [1], each one of the preceding images did to some extent affect the current perceived image of Egyptian cities. This investigation focuses on the Islamic period (650A.C-1800A.C) because it still affects the visual appearance of the Egyptian cities until now. Most Egyptian cities still include areas which belong to the Islamic period and continue presenting the character of the Islamic city through its buildings and streets [1].

Generally, all Islamic empires or dynasties have always been known for the development of cities with special characteristics considering the social and environmental issues rather than the economic and geographical factors. The planning of such cities took into account what would promote the physical and spiritual growth of their inhabitants [2] (See Figure 1). It is a big mistake to state that all Islamic cities has the same visual image or the same characteristics because each city has its own image according to the forces and factors which give this image its distinguished and memorable character as shown in Figure 2.

One of the distinctive features of the Egyptian Islamic city image is its robustness. Because these cities were built of stone or bricks and did not suffer from fires which usually was the main cause of the destruction of towns using timber as building material (such as the case of Istanbul). Therefore the durable visual image of the Egyptian cities still tell the story of their origins and convey the historical values of their community [3].

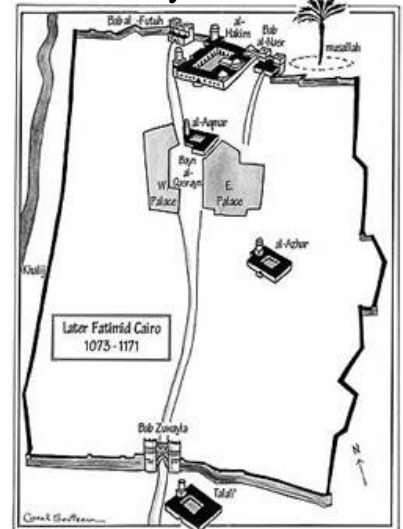

Fig. 1. The Fatimid plan of Cairo (1073-1171) [4].

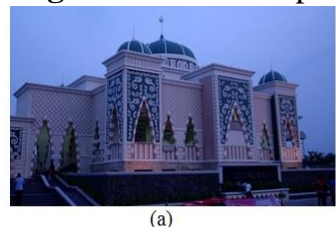

(a)

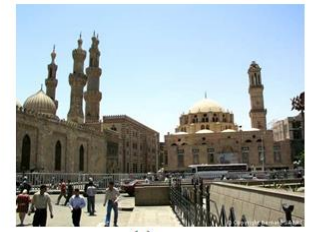

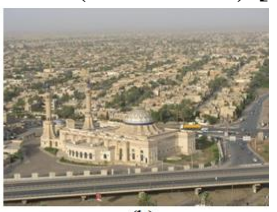

(b)

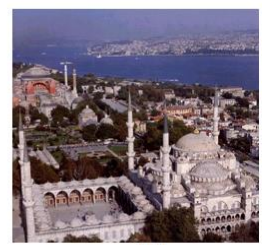

Fig. 2. Examples from different Islamic countries to prove that each Islamic country has its own image. (a) Al Taubah Mosque in Jakarta, Indonesia [5], (b) Al Nida Mosque in Baghdad, Iraq [5], (c) Islamic Cairo, Egypt [6], and (d) The Blue Mosque in front of Hagia Sofia in Istanbul, Turkey[7] 


\section{Literature review}

Orientalists - the traditional term for western scholars who studied the eastern languages, culture and history [8] drew their definition from medieval Muslim writers who considered the Islamic city simply as a place with a Friday mosque, a market and a public bath. This definition, however, makes no distinction between city, town and village as each may have all the three essential features. This classical model which depended on the idea that Islam was an urban religion was widely disseminated through a whole generation of scholars uncritically cited or incorporated others work into their own [9]. The concept of Islamic City was consolidated and debated since 1920s to understand the essence of the issue and the source of the theory [10].

Nezzar Al Sayyed described Islamic cities as following 'Muslim cities are selfcontained entities that make up a distinct society and culture radically different from that of other civilization.' [11:p.1]. The fact is that most studies [12-14] which investigate the design of Islamic cities still focus on a single case and try to generalize. But actually no one can expect that all Islamic cities have similar images [15].

Orientalists focused on the physical components of the Islamic city, compared the model of Islamic city to the Western city model and looked for a universal Islamic city image as a stereotype [16]. On the other hand, modern scholars continued the Orientalists' thought but by adding the social approach to their studies [17]. Much research refers to the importance of preservation of the historic urban fabric and identified the factors that affect the success of preservation within the initiatives for regenerating the image of the city $[17,18]$.

Many researchers have analysed the images of the Egyptian city from cultural, social and historical viewpoints. But only a few number of researchers dealt with the image of townscape, urban character and the visual determinants [19]. Abdel Baki Ibrahim has investigated the urban reforms of the Egyptian city during the various Islamic empires [20].

Some authors have addressed questions regarding the future of Islamic cultural heritage and historical areas preservation $[1,18]$. Most of recent studies try to find approaches and methods to sustain the heritage qualities and integrate them into a contemporary design language [2, 18]. Ahmed Sedky in his book 'Living with Heritage in Cairo, Area Conservation in the Arab-Islamic City' discussed the quality of area conservation and how can it evaluated. He found answers to some questions in terms of what to conserve and how to conserve? However these questions are very important to the future of the Islamic city and its sustainability, the attempts to answer them lacks the practicality.

Some studies suggested partial solutions for the problem of losing the identity of Islamic city. These studies focused on either the use of traditional materials or applying the Islamic aspects to the facades of modern buildings. However, these ideas cannot impact the image of the city effectively because of the non-existence of a comprehensive and holistic approach informed by the conceptual Islamic form of the city, rather than the mere use of materials, colours or the outer forms of Islamic urban fabrics as shown in Figure 3. The Islamic image could be sustained through the compromise between the Islamic values and traditions as constants and building materials, building technologies and spatial order of the urban objects as variables [1]. Applying this way of thinking can present a wide range of possibilities and ideas to improve the image of the Egyptian city without breaking its cultural and historic boundaries. 

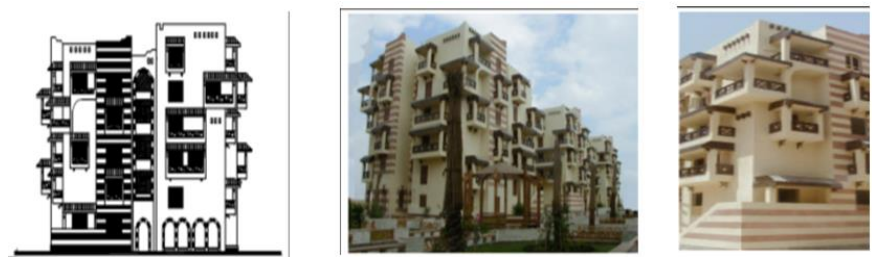

Fig. 3. Applying the traditional style of the Islamic facades with bright colours and Mashrabyas to the contemporary buildings is a partial solution for the identity problem.

Kevin Lynch in his book 'The image of the city', tried to probe through mental mapping, the psychology of spatial borders and spatial concepts. He concluded that, some quarters and cities are more 'imageable' than others [21]. There is no doubt that the historic quarters which are often located in the central areas of Egyptian cities were built to be imageable.

\section{Methodology}

Applying Lynch analysis to the image of the Islamic Egyptian city centres is used in this paper to put hands on the negative and positive features of this particular image according to the Lynchian criteria of imageability, liveability and permeability. The analytical approach is used here to translate the investigated image of the Islamic Egyptian city to general concepts which can be applied to the contemporary image in various ways. The following diagram clarifies the methodologies which are used in this research paper.

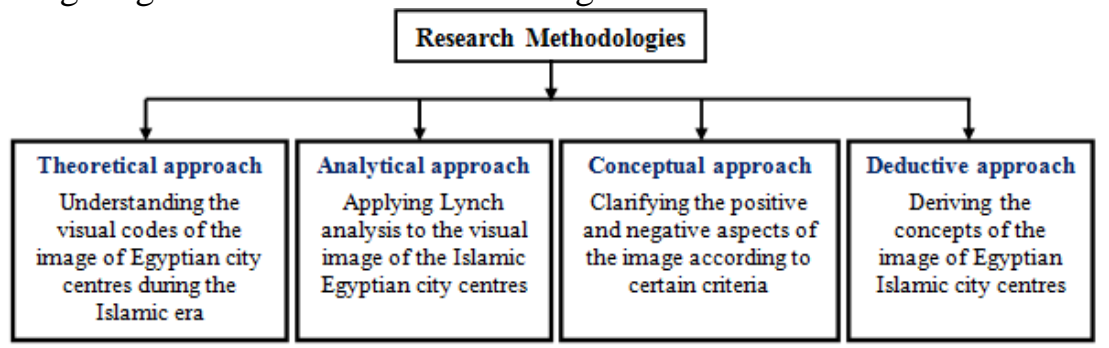

Fig. 4. The research methodologies.

\section{Understanding the visual codes of the image of Egyptian city during the Islamic era}

Derrida Nichols defined the perception as 'Perception depends on coding the world into iconic signs that can re-present it within our mind' [22]. The Arab geographer and philosopher Ibn-Khaldun described the Islamic city as the city which must have a congregational Friday Mosque and a market nearby (See Figure 5). However, the residential districts are located in the distant sectors. This graduation of the urban patterns is based on the concept of privacy and of dampening noise levels gradually from the busy city centre to quiet residential districts [23]. The centre of the Islamic Egyptian city was a multifunctional district (See Figure 6). It displayed three types of centres: the religious centre, the educational centre and the commercial centre through a great number of different types of public buildings. The centre had a unique image which could be viewed, heard and smelled.

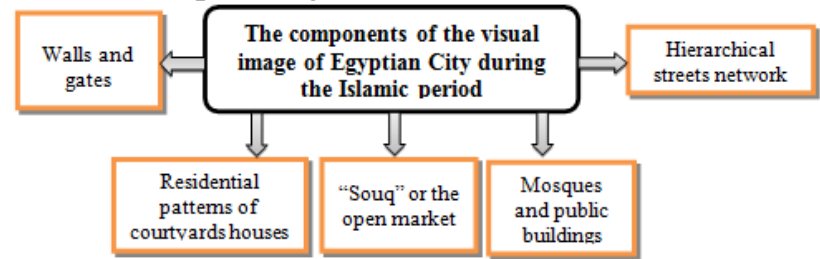

Fig. 5. The components of the visual image of Egyptian city during the Islamic period 


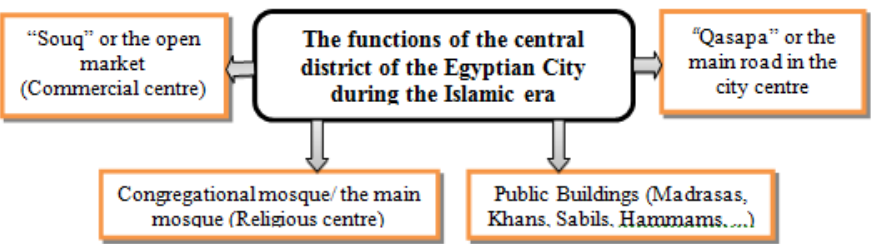

Fig. 6. The components of the visual image of Egyptian city Centre during the Islamic period

The image of Egyptian city during the Islamic era demonstrated certain visual rules which have been applied to buildings and spaces in order to create cohesive and harmonic urban order. Islamic Architecture displayed the concept of symmetry in most of its forms in plans, elevations and elements of ornamentation of mosques and houses. The concept of centralisation was applied to the open spaces such as courts and gardens [19]. Thus the image of Egyptian city during the Islamic era reflected the sense of harmony, unity and rhythm between its different parts. It is important to determine the underlying factors which affected the appearance of the Egyptian city during the Islamic era. These factors are summarized as following:

- The religious and cultural factors.

- The climate and natural laws.

- The social factors.

- The available materials and construction style.

- The Islamic legislation (Share'a).

- The economic factor.

\section{Lynch analysis of the Egyptian cities during the Islamic period}

Lynch defines the image of the city through five components in order to help in understanding the urban features of the city [21]. The five components of the Egyptian image during the Islamic era are investigated in the following paragraphs:

\subsection{Districts}

Districts of the Egyptian Islamic city are the areas whose central nodes are the Friday mosques. The most important buildings scattered along the main linear space which branches out into the city patterns forming irregular specialized markets. The boundaries of these districts are controlled by a citadel or a defensive post on the outskirts which tie well with the city walls [11].

The main feature of the districts structure in the Islamic era is the clear separation of commercial areas and residential areas. All markets occupied the central district which did not include any residential uses [24]. This sharp segregation between the residential and commercial quarters in the classic Islamic cities has been attributed to the need for privacy to the houses and this separation helped to gain control all over the city [15].The city centre as shown in Figure 7 was occupied by the great mosque (the religious centre) and the public buildings such as 'Madrasa' (The educational and intellectual centre). Near the religious centre, it is found the books stores and binders. Markets 'Al-Qaysaria' were found not far from the great mosque. 'AlQaysaria' was a secure place encircled by walls, where foreign merchants, above all Christians, used to come to display their cloth materials brought from European cities.

Buildings were shaped according to the needs of the users and to the adaptation with climate. Therefore buildings constituted enclosed areas as integral entities with their own resources of air, light and open space independent of the street space. Islamic buildings such as mosques have traditionally incorporated minimal furniture in order to emphasize the 
enclosure of this divine space, which is defined by the building's structural design; its facade, materiality, vertical and horizontal lines and the ways that light addresses the structure [25]. Compact urban fabric as shown in Figure 8, shaded streets, narrow passageways and unique design of facades demonstrate how the design of buildings and city planning work together in respect to the climate conditions and the factor of thermal comfort [23].

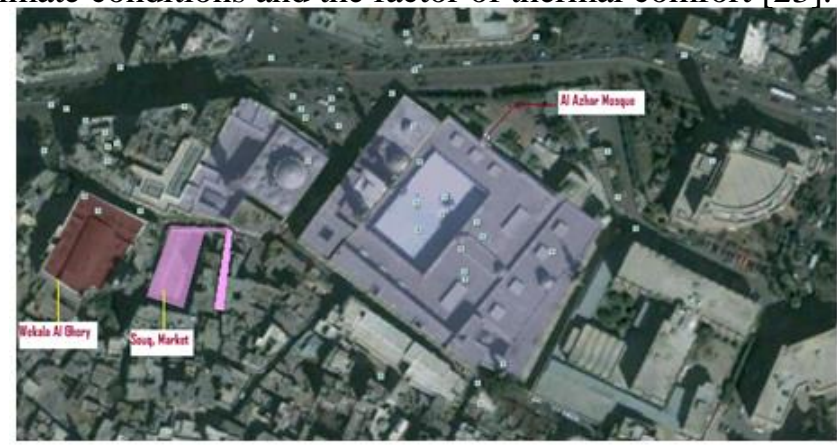

Fig .7. The main buildings in the central district of Islamic Cairo

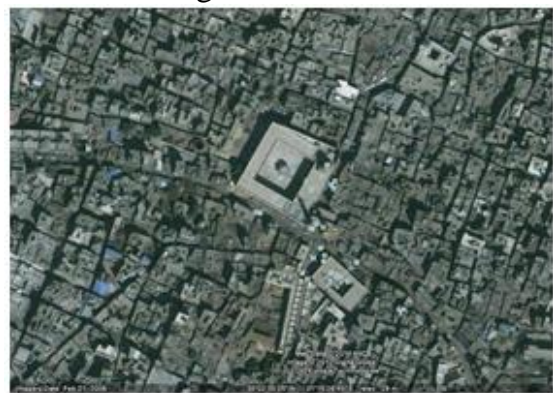

Fig. 8. The compacted patterns of buildings with courtyards decrease the sense of high temperature and humidity and provide more shaded area

The different built objects of the city are observed as a single complex structure because it is difficult to distinguish the buildings individually. The built masses took this solid form for many reasons; to avoid the sharp sunlight during summer, to provide a protection against extreme high temperatures and sand storms, to minimize the thermal load on the buildings envelopes especially houses and to demonstrate the concept of unity which is an important concept in the Islamic religion. The central courtyards with their natural elements played an important role to provide the amenity and comfort for the users and the visual delight for the observers. The compacted patterns of the city centre reduced the time and the long of journeys and encouraged the pedestrian movement [19].

Regarding the shape of the city patterns, the division of lands was seldom done with geometric order. The traditional urban patterns were divided according to: firstly, the ethnicity and the religion of the inhabitants therefore there were some districts for Muslims, for Christians and others of Jews. Secondly, the maximum walking distance between the central mosque and the other neighbourhoods because the Islamic cities were planned using the pedestrian scale. Thirdly, the maximum distance over which the residents were able to hear the voice of the 'Moazen' (the man who calls the prayers) when he tells 'Al-Azan' (the call for pray) [16].

Mosque for Islamic city is not considered as its religious centre only but as the central object of the city image. Therefore, the districts were clustered around mosques to keep them visible. The image of the Islamic urban patterns was articulated by its compact and dense texture which lacked the openness of spaces except the area surrounding the main mosque in the city centre. 
Obviously, there is a contrast between the image of the central district and other areas of the city in terms of land uses, streets straightness which is different from the narrow and curved streets in the other districts and lastly, the existence of relatively high buildings such as minarets, defence towers and high gates which were not found in the other areas which were built with one or two floors [24].

Al-Qaiserya (see Figure 9) could be considered as the most vital part of the image of the city centre because of the various activities such as the trade of textiles and jewellers which took place in these linear spaces. This area had special physical characteristics. These commercial passages provided a feasible climate for users by their light roofs which were made by some kinds of textile [15].

"Wekalah" was the only type of residential building in the centre of the city. The upper floors of the building were utilized as a hotel for visiting merchants. Those floors contained three levels apartments with a private entrance to each unit. Public buildings such as "Hammam", "Sabil" and "Madrasa" provided different social and educational activities to the central district as shown in Figure 10.
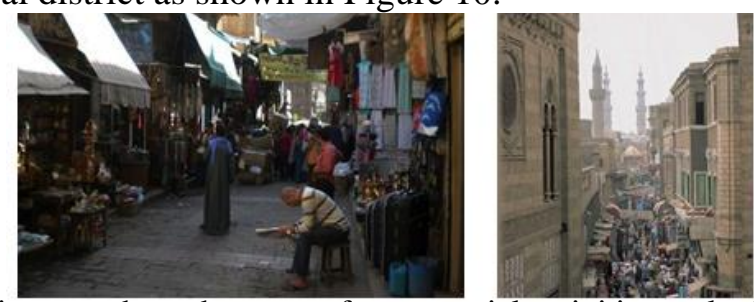

Fig. 9. Left: Al-Qaiserya, where the most of commercial activities took place still operative until today, right: Textile trade was located in Al Ghuriya, close to the central mosque, Al Azhar [26]
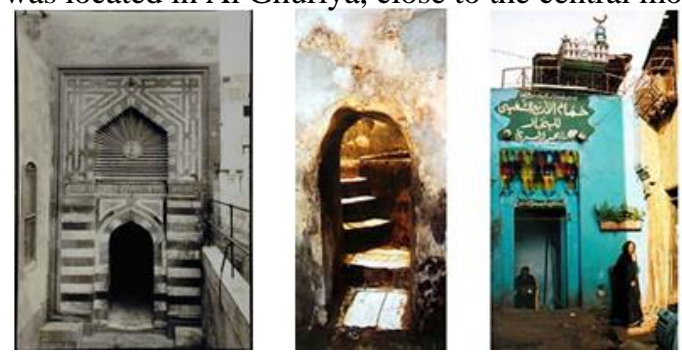

Fig. 10. Examples of public buildings. Left: Hammam of Amir Beshtak was built in 1335 by using the Mamluk style [27], middle: Hammam Al-Malatili, a gateway to beauty and relaxation [28] and right: The entrance to Hammam Al-Arba' [29]

However the properties were continuously subdivided which led to uncontrollable size of urban environment, each district was strongly bounded and isolated from other districts by walls or gates which helped observers to understand and perceive the character of each district easily.

\subsection{Edges}

The image of the classical Islamic city was strongly bounded by walls and gates (see Figure 12). The Nile River is the dominant natural edge of the image of Egyptian city. This dynamic edge plays an important role in improving the legibility of the image and creating the sense of identity. 

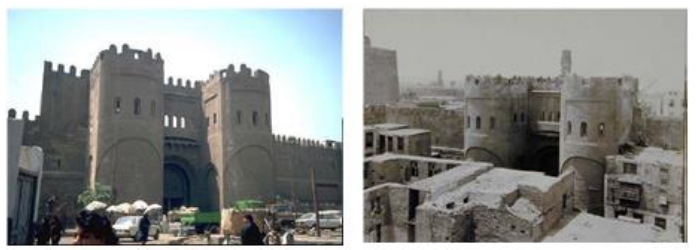

Fig. 12. Examples of gates and walls. The gate of Al-Futuh 'Bab Al-Futuh' was built in 1087 as part of Cairo city walls, Cairo, Egypt [30]

\subsection{Paths}

The image of the streets network demonstrated two types of roads: the first type was called 'Qasapa' which extended from North to South and carried most of the commercial activities. The second type went from East to West and led to the main gates of the city. The great mosque was located in the intersection of these two roads. There were also some lanes 'zuqaq' which intersected with the main streets. Gates were found in these points of intersections. Alleys and cul-de-sacs were found in the residential areas because this type of streets is safe and it gives the users the senses of protection, belonging and a territory [31]. The image of the central area is distinctive by its network of relatively large and straight streets leading direct to the main gates (Raymond, 1994). Traditionally, the nested hierarchies as shown in Figure 13 were created through a process of agglomeration rather than subdivision. Streets were not laid out as in American and European cities after the mid-19th century but streets were composed of leftover space after houses were built. Consequently, wide streets were considered a waste of space [32]. Most of the streets had the same streetscape which consists of a repetition of solid buildings facades which were built of stone as shown in Figure 14. On the other hand, the mosques' facades were decorated very richly and their minarets acted as vistas for the main streets (see Figure 15). Figure 16 illustrates the streetscape of Islamic Egyptian central districts.

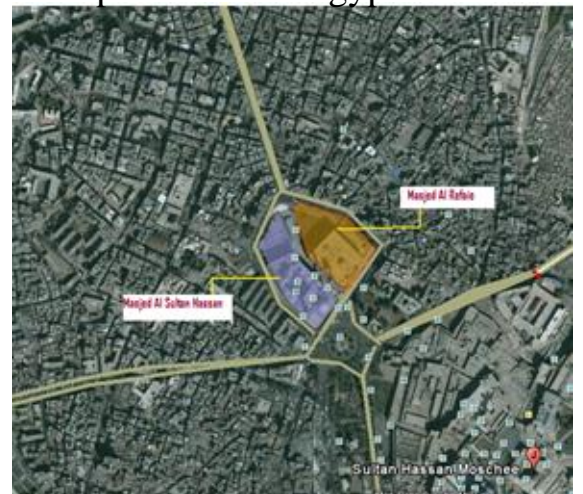

Fig. 13. Aerial view of Islamic Cairo illustrates the two main streets in the city and the main mosque is located in the intersection of them

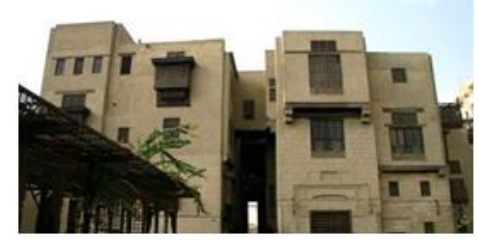

Fig. 14. Bayt al- Kritilya shows the architectural characteristics of Islamic houses; the height of which is 2-3 floors, the solid facades and the woody windows with the work of the 'Mashrabya' [33] 


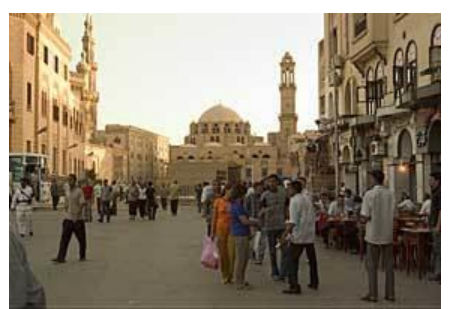

Fig .15. The high minarets represented the most dominant vistas for streets in the Islamic city [34]
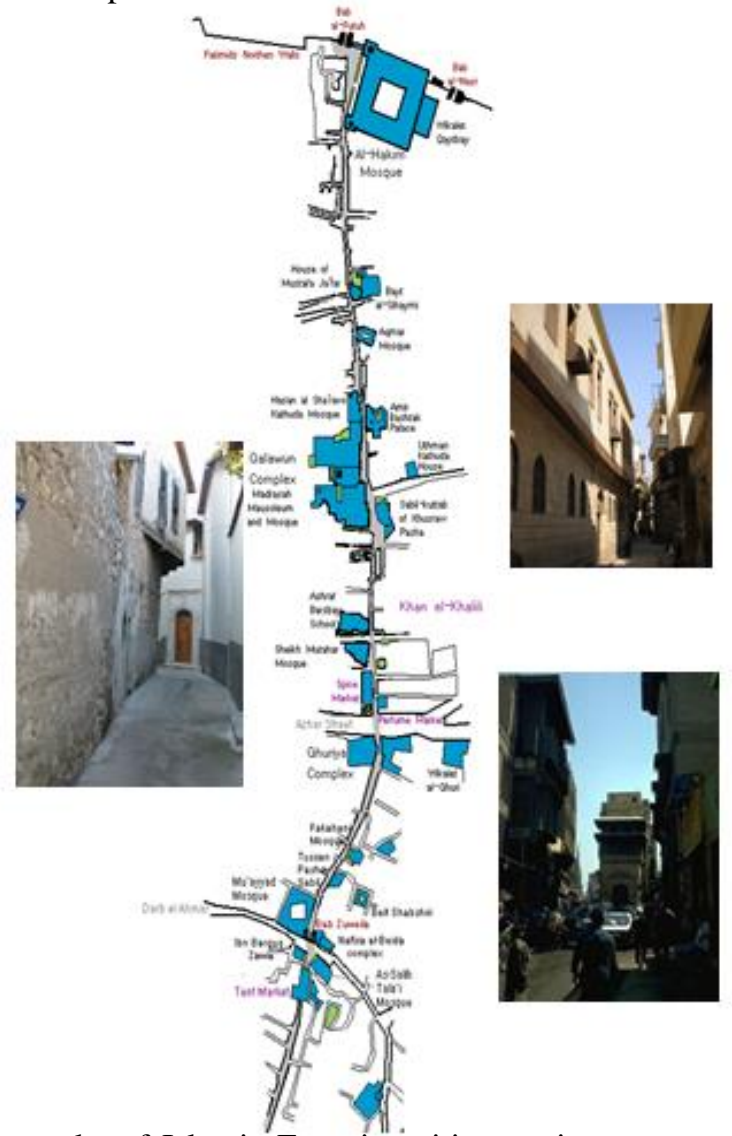

Fig. 16. The street networks of Islamic Egyptian cities: various types of streets include main roads, Cul-De Sac and narrow lanes [35]

\subsection{Landmarks}

The political and religious forces have formed the skyline of the Egyptian city in the Islamic period. Therefore the skyline included various styles of minarets and domes which represented the traditional landmarks of the city as shown in figures 17 and 18. The citadel and defence towers represented another type of landmarks at that time.
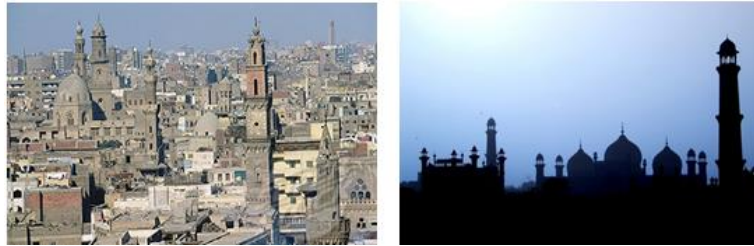

Fig. 17. Minarets and domes are the most dominant landmarks in the Islamic city [36] \& [37] 


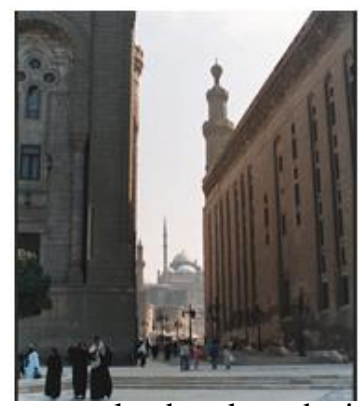

Fig. 18. Mohamed Ali Citadel acts as landmark and vista which can be seen from several observation points because of its high location in the area of Al-Darb Al-Ahmar, Islamic Cairo [38]

\subsection{Nodes}

At the large scale, the court or 'Finaa' of Friday mosque in addition to the area surrounding the mosque was the main public node of the Egyptian city in the Islamic age (See Figure 19). This node was distinguished by its distinct geometric form, special treatment of floor, central pool or fountain and the high density of users and human activities.

At the small scale, the courtyards of big houses can be considered as local nodes for residential areas. Such pr ivate nodes were used for different social activities
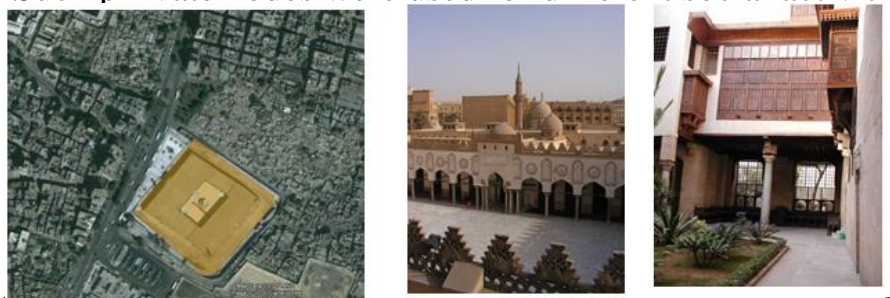

Fig. 19. Left: Aerial view of the courtyard or 'Finaa' of Al-Azhar Mosque in Cairo [39], middle:

\section{The overhead image as a way of the Islamic image perception}

Considering the potential of observing cities from high levels should be taken into account because it affects the decisions about the design of the city or improving its image. Understanding from where and how this over-head perspective can be observed is an important concept in designing the city in terms of the location of high buildings, the utilization of rooftops, the optimisation of aspects and prospects and other parameters which affect the visual appearance of the city [41].

The high minarets of mosques and the high openings of defence towers, walls and gates can be considered as the main observation points from where the image of the city can be viewed from above (See Figure 20). Observing the city from overhead reveals the different parts of the city through the wide view angle of this panoramic field of vision. Such image was observed by particular type of city observers such sheikhs (Muslim clerics) and Moazens (men who call the prayer to do the pray) who used the high minarets to communicate with the public in special occasions. On the other hand, there is another type of city observers who worked to protect the city and to control its gates. Viewing the city from the high, narrow and long openings of the gates or towers provided a limited view angle which protected the observers and help them to be not seen from outside and to make a visual control on the city. Thus it could be said that, the high locations of vision have been utilized during the Islamic era for the religious and defensive purposes. 

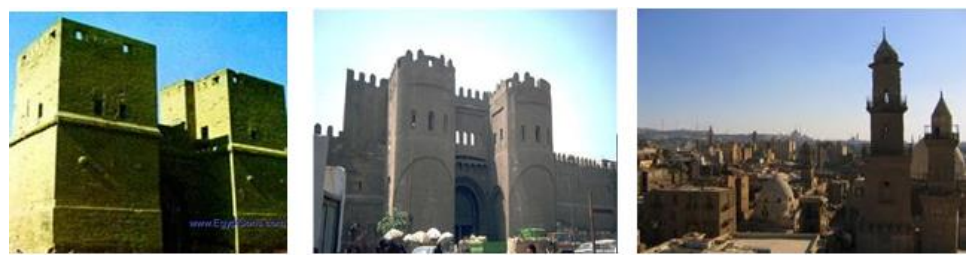

Fig. 20. Viewing the city from above through the high openings of gates and walls and the high minarets $[33,42]$

\section{An evaluation of the visual quality of the Islamic image}

It is very important to consider the results of urban analysis and to move from the descriptive mood to the analytical stage which helps to evaluate the image of the city according to certain criteria such as variety, legibility, permeability and so on. The unique visual attributes and expressive visual scenes of the image of the Egyptian cities succeeded in conveying the cultural and religious values of the community during the Islamic era. The cohesive structure of the city was clear and met the criteria of identity, privacy and balance of land uses according to the users' needs. The inward form of the city demonstrated great adaptability and response to the climate conditions which led to achieve the criteria of amenity and thermal comfort. Although the image of the Egyptian city through the Islamic era presented many positive aspects which have been investigated widely in many research studies, some visual problems can be recognized as following:

\subsection{The shortage of accessibility}

According to the security rules, the gates which led to the city centre used to be closed at night which affected the level of permeability and accessibility and reduced the available choices of movement.

\subsection{The absence of legible streets networ}

The streets planning of the Islamic city did not conform to any geometrical or formal grid. Therefore the image of streets network is difficult to be read especially from the street level. It lacks the senses of orientation and visual order. Most of the streets had the same streetscape especially in the residential areas. The narrow, irregular and disorganized streets did not provide any opportunity for street furniture to be found. Using the hierarchical system in streets planning in addition to the coherence and solid inward patterns of buildings affected negatively the physical and visual permeability of the city. Furthermore, the concentration of most human activities in the main roads which surrounded the main mosque affected the viability and liveability of the residential areas [see Figure 21].

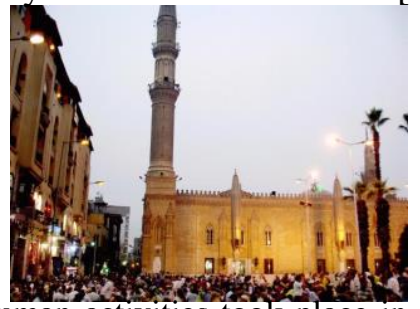

Fig. 21. The high density of human activities took place in the open public spaces around the main mosques in the city centre. Al- Hussien Mosque in Cairo [40]

\subsection{The closed fields of vision}

The Islamic Egyptian city lacks open spaces in most of its parts except the area of the main market 'Souq'. It is difficult to find any public open spaces for recreational purposes. 
While the only public open space in the city was the court of the congregational mosque and the area surrounding it, the city included many private semi-open spaces such as the houses courtyards. These private spaces had very limited views toward the city because the users were oriented inward to observe the local view of the courtyard rather than viewing the edges and the surrounding landscape as shown in Figure 22.
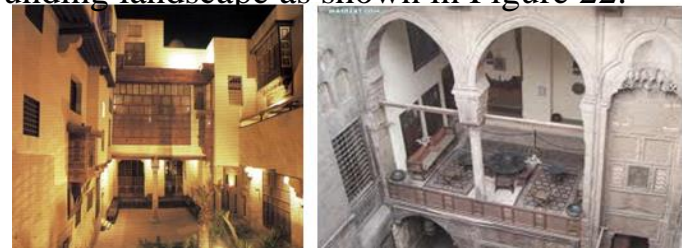

Fig. 22. The courtyards of houses as semi-open spaces which have limited views toward the city. The internal courtyard of Bayt Al Soheimy [43]

\section{The relevance of the Islamic image to the contemporary city}

New models of built environments need to interact directly with the traditional forms in order to take advantages of them. Also these new models need to use the scientific, technical and architectural tools which are available today in applying the positive aspects of the historic images to the contemporary image of the city. So heritage and traditional architecture should be adapted to develop a new paradigm which does not break the traditional frame of the image.

Practically, some cities seek to improve or conserve the image of the old and historical areas in order to maintain its identity. This approach is not sufficient and has not effective impact on the comprehensive image because applying this approach creates cities inside cities and produces contrast images full of contradictions. Another approach which is used currently to connect the contemporary design of the city with its historical images is to work at the levels of materiality, colours, texture and outer forms of the buildings. This can result in hybrid buildings where traditional facades of arches and domes are attached to modern high-rises [44]. Such approach seems to be not comprehensive because it focuses on the visual attributes only and ignores the rules, constants and concepts which produced the traditional images. The use of Islamic style of facades such as wooden windows 'Mashrabyas', Islamic ornamentation and textures cannot elevate or satisfy the public's taste and performance standards of the 21th Century and at the same time it could not regain the lost identity because it does not affect the whole image of the city. Rethinking the historical images of the Egyptian city especially the Islamic image should go through deriving the general concepts of these traditional forms and convert them to certain criteria and considerations that should be taken into account in the process of designing the contemporary city without repeating the old architectural forms or using the traditional tools to achieve these criteria. Furthermore, these criteria should not be applied to only the new buildings which will be constructed in the historical areas. All areas should be affected by these criteria by using different tools to produce a consistent, cohesive and unique image of the city.

The following paragraphs summaries the main principles which can be derived from the Islamic version of the city image. These principles can be applied to the contemporary image of the Egyptian city by different methods to make it unique.

\subsection{Community-based city design}

The term Islamic city implies the power of the social factor and means that the community and its religion, customs, beliefs and culture control the form of the city. Oppositely, the design of modern Egyptian cities is affected by the globalization and 
economical changes as major factors and ignores the social needs of their communities. This leads to the loss of identity and legibility.

"Construction of the Islamic neighbourhood starts with the dwelling unit of the family that keeps to Islamic values, which is reflected on its architectural design as well as its structure taking a balanced form that fulfils our requirements of equipment, as also carries out requirements of privacy, dignity, health and security, within the family means. " [44, p: 7-8].

The most useful lesson from the design of Egyptian city in the Islamic era is the interaction between the city and its users and the use of social approach of designing the city. Consequently, the city users sustained the sense of belonging. To design the city in a way that makes a city works for its residents is an important task or challenge in order to reach the uniqueness of the city image.

\subsection{The balance between visual exposure and privacy}

The balance between visual openness and the concept of privacy has been taken into account in the Islamic city design. Privacy is the major aspect which influenced the quality of human environment in Islamic cities. Therefore the opened views were located carefully and they were used to highlight the most important and valuable urban objects such as mosques, citadels and Nile River which can be seen from several observation points. On the other hand, the use of gates and narrow streets which limit the field of vision was found in the residential areas because they need to be visually protected. Combining the two approaches of visual openness and blocked views should be conducted in a balanced way in order to support the concept of privacy which is lost in the most of contemporary cities in Egypt.

\subsection{Design for climate [1]}

The response of the city design to the climatic conditions was represented by the introverted courthouses, the use of roof terraces as shown in Figure 23, wind catchers and the compact form of solid masses in order to maximize shading. Vernacular architecture in the Islamic world is considered as a perfect response to the living conditions of both the natural and social environment.
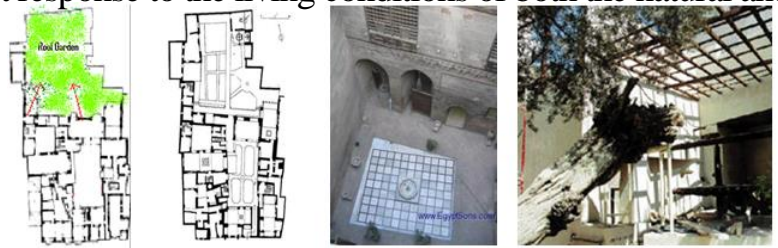

Fig. 23. The gradual form of the mass creates more top surfaces which were used as roof gardens. Bayt Al-Soheimy, Cairo, Egypt [45, 46]

One of the distinguished features of the Islamic city is the preference of certain building techniques and materials which give protection against the extreme heat and humidity of the summer and the cold winter nights because of their low thermal conductivity such as wood, brick and the use of vaulting and arcades. This environmental approach of designing the city is very important to be taken into account during designing the contemporary Egyptian city.

\section{Conclusion}

A place is always more than just what is there on the ground. It is a system of thinking and perceiving through the time. The historical images of the city help in understanding the values, lifestyles and cultures of the city users through the time. The image of the city with central mosque, courtyard houses, public buildings, hierarchical streets network, 
distinguished skyline and senses of privacy and identity express loudly the nature of the Islamic community: its culture, religion and social values. This image was distinguished by its inward and compact form, irregular and narrow streets and its edges with walls and gates. The users of such cities enjoyed the sense of identity, harmony, unity and privacy.

The design of Islamic cities considered effectively the natural laws by applying some concepts which improved the environmental performance of the city and developed the sense of thermal comfort. On the contrary, the image of Egyptian city during the Islamic era has some visual and urban problems such as the absence of open and panoramic fields of vision and the difficulty of understanding the structure of the streets network which produced the sense of disorientation. The limited opportunities to view the city from high levels of vision affected the level of visual permeability and reduced the ability of experiencing the wider city through the panoramic field of overhead perspective. Additionally, the shortage of accessibility to the city centre at night which reduced the viability of the night images.

Regarding the relation between the Islamic image and modern image of the Egyptian city, the absence of any correlation between the principles of visual design which was applied in the Islamic city and the morphological characteristics of the modern image of Egyptian cities could be the main reason behind the visual problems and identity crises of our urban communities. The old areas in any Egyptian city can be observed as a city inside the city. This means that there are no sharing images between the old and modern areas of the city.

Rethinking the image of the Egyptian city can be articulated by incorporating the historical and modern images in an entity. This integration can be achieved by introducing new understanding that will find a way to connect the city with the local regional heritage and at the same time to make the city works within the global realm. It is focused here on the importance of understanding the conceptual framework of Islamic architecture and to allow modern building technology to be a tool in the expression of the essence of the Islamic architecture. The relationship between Islamic architecture as a cultural paradigm and modern civilization as an ideology of technical development should be considered carefully. If these considerations are kept in mind, new construction can add value to the city without contradicting the existing unique assets of historic architecture.

The challenge for the future is to develop processes of city design which can be guided by design criteria derived from the historical images of the city. It is focused here on the guiding principles which can be inspired from the image of Egyptian city during the Islamic era and their reflections on the current image of the city. Some design principles such as communitybased city design, the balance between the visual exposure and privacy and the design for climate can be applied using the available new techniques in order to fill the gap between the needs of the users and the visual attributes of the image which is observed by these users. So what can be effective to regain the uniqueness of the Egyptian cities images is to walk in the same road of the traditional qualitative city image but in different steps and by different feet.

\section{REFERENCES}

[1] Eldemery, I. M., "Islamic Architecture: Cultural Heritage and Future Challenges," The First International Conference of the UIA-WPAHR-V on Architecture \& Heritage as a Paradigm for Knowledge and Development Lessons of the Past, New Inventions and Future Challenges, Alexandria, Egypt, pp. 99-110, March 2-4, 2002.

[2] Buaben, J., "What makes a 'Good City'? A Muslim Perspective," Adopted from internet on 03.01.2020 at: http://www.faithsforthecity.org.uk/Papers/Islam.pdf. 
[3] Denoix, S. "History and Urban Forms: A Methodological Approach," In Environmental Design: Journal of the Islamic Environmental Design Research Centre 1-2, pp. 70-81, 1993.

[4] Bierman, I. A. "Writing Signs: The Fatimid Public Text." Berkeley-Los AngelesLondon: University of California Press, 1998.

[5] http://iwritealot.com

[6] www.art-photo.fr

[7] http://booktravelpro.com

[8] www.macmillandictionary.com

[9] Abu-Lughod, J. "The Islamic City: Historic Myth, Islamic Essence, and Contemporary Relevance." Urban Development in the Muslim World. Ed. Hooshang Amirahmadi and Salah S. El-Shakhs. New Brunswick, NJ: Center for Urban Policy Research, pp. 11-36, 1993.

[10] Haneda, M. and Miura, T. "Islamic Urban Studies: Historical Review and Perspectives," USA and Canada: Routledge, 2010.

[11] Al Sayyed, N. "Cities and Caliphs: On the Genesis of Arab Muslim Urbanism," New York: Greenwood Press, 1991.

[12] Hakim, B. S. "Arabic-Islamic Cities: Building and Planning Principles," London: Kegan Paul, 1996.

[13] Mortada, H. "Traditional Islamic Principles of Built Environment." London and New York: Routledge Curzon, 2003.

[14] Saoud, R. "Introduction to the Islamic City." Manchester, United Kingdom: The Centre of Foundation for Science Technology and Civilisation, FSTC Limited, 2002.

[15] Woodberry, J. D. "Muslim Cities." Urban Mission Journal, 15 (3), 1998.

[16] Asfour, K. "Social Health in the Arab City." Eastern Mediterranean Health Journal, 1 (1), pp. 96-102, 1995.

[17] Sedky, A. "Heritage of Cairo: Area Conservation in the Arab - Islamic City," Cairo, Egypt: The American University Press, 2009.

[18] Abu-Lughod, J. "The Islamic City -Historic Myth, Islamic Essence, and Contemporary Relevance." Chapter in "Urban Design Reader" ed. Michael Laris and Elizabeth Macdonald, USA and Canada: Routledge, 2013.

[19] Ali, E. "Visual Design Guidelines for Medium Sized Cities - The Case of El Menya City - Egypt." Ph.D. thesis, Faculty of Architecture and City Planning, University of Stuttgart, Stuttgart, Germany, 2003.

[20] Singerman, D. and Amar, P. "Cairo Cosmopolitan: Politics, Culture and Urban Space in the New Globalized Middle East." Cairo: American University Press, 2009.

[21] Lynch, K. "The Image of the City." Cambridge MA: MIT Press, 1960.

[22] Bill, N. "Ideology and the Image: Social Representation in the Cinema and Other Media." Bloomington: Indiana University Press, 1981.

[23] Al-Zubaidi, M. "The Efficiency of Thermal Performance of the Desert Buildings - The Traditional House of Ghadames, Libya." Annual Conference of the Canadian Society for Civil Engineering, Montréal, Québec, Canada, 2002.

[24] Raymond, A. "Islamic City: Orientalist Myths and Recent Views," British Journal of Middle Eastern Studies, 21, (1), pages: 3-18, 1994.

[25] Ramon, J. C., "The Use of Light in Islamic Architecture," People of our everyday life, URL: http://peopleof.oureverydaylife.com. 2012.

[26] www.museumwnf.org

[27] http://en.wikipedia.org

[28] Abdel-Moneim, A., “A Day at the Baths.” Al Ahram Weekly online, 4-10 December 2003.

[29] http://weekly.ahram.org.eg

[30] www.touregypt.net

[31] Bala, H. A. and Nafa, H., "The cul-de-sac, Private Streets, Public Spaces." On Site Review Magazine, Canada, URL: www.onsitereview.blogspot.com, October 2008.

[32] Good, D. "The Middle Eastern Islamic City: Type and Morphology." San Francisco University, URL: bss.sfsu.edu, 2003.

[33] http://mag.egyptsons.com 
[34] www.alclass.co

[35] www.albab.com

[36] www.istockphoto,com

[37] http://usaislam.rigala.net

[38] http://static.panoramio.com

[39] www.sacred.destinations.com

[40] http://upload.wikimedia.org

[41] Moubarak, L. M., Bush, J., Radwan, M., Salah, K. "Conceptualizing the Perceptual Changes of City Imaging and Their Impact on Urban Design." The International Journal of the Image 2 (2), pp: 211-240, 2012. DOI: 10.18848/2154-8560/CGP/v02i02/44252

[42] www.fotopedia.com

[43] www.egyptarch.com

[44] Saqqaf, A. "The Middle East City, Ancient Traditions Confront a Modern World." New York: Paragon House Publisher, 1987.

[45] Moubarak, L. M. "Urban Bird-Eye View of Contemporary Egyptian Cities - Active and Passive Aspects." M.Sc. Thesis, South Valley University, Aswan, Egypt, 2004.

[46] www.ahram.org.eg/Archive

\section{Glossary of Arabic terminologies}

- Bayt: House

- Mashrabya: Wooden grill or screen

- Sabil: Educational, waterwork and religious building

- Hammam: a steam bath, which can be categorized as a wet relative of the sauna. It had played an important role in cultures of the Middle-East, serving as places of social gathering

- Finaa: Courtyard

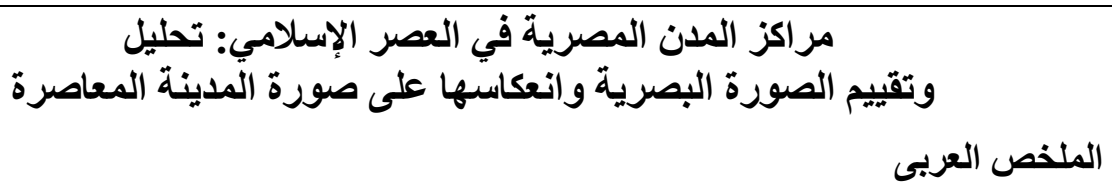

يثتمل مركز المدينة المصرية في العصور الإسلامية على معظم العناصر المعمارية والعمر انية المميزة من حيث المباثية التشكيل

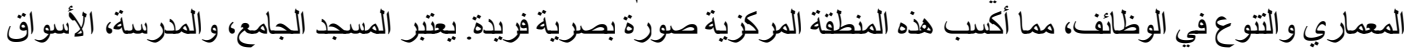

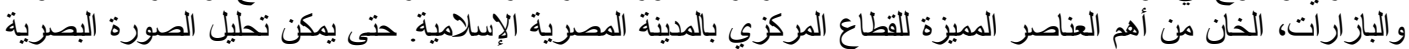

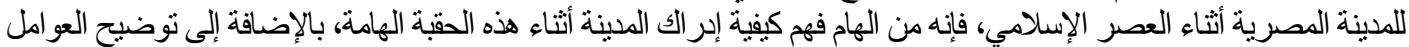

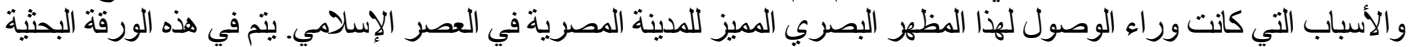

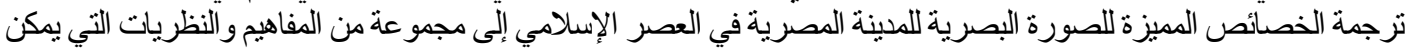

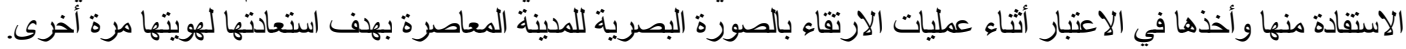

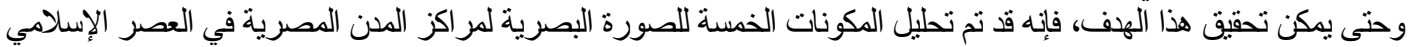

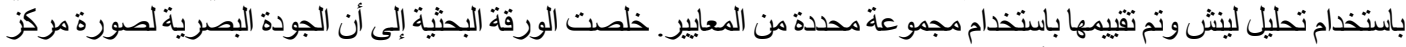

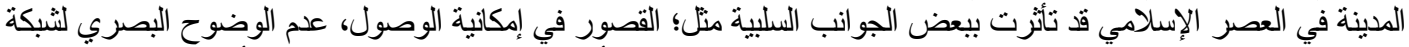

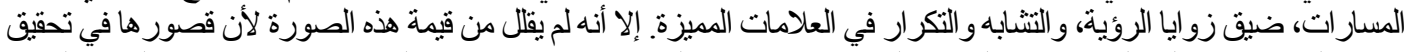

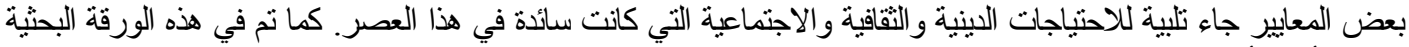

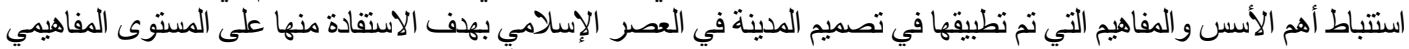

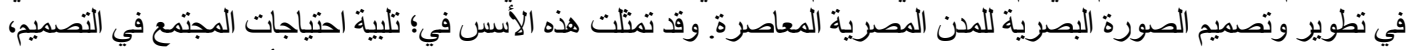

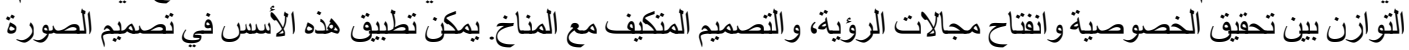

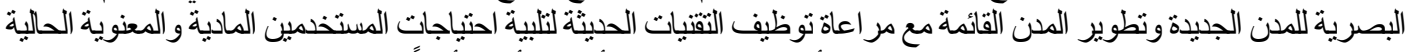

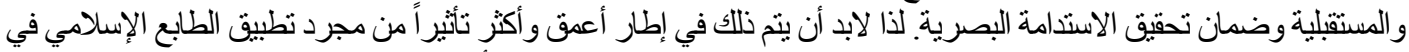

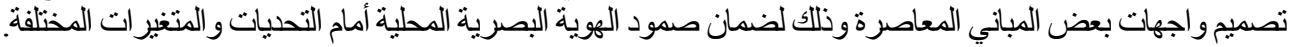

الكلمات المفتحيَّ: صورة المينة المصرية، المينة الإسلامية، تحليل لينش، التصميم الحضري، العمارة الإسلامية، الصور العوية. 